\title{
Research on Spiral Model of College-enterprise Collaborative Education in Private Colleges-A Case Study of Information Technology Major
}

\author{
Zhiguo Bian ${ }^{1}$, Ming $\mathrm{Li}^{1,2,}{ }^{*}$, Guangyun $\mathrm{Lu}^{1}$ and Mingyan $\mathrm{Wu}^{2}$ \\ ${ }^{1}$ School of Economics \& Management, Liuzhou Institute of Technology, Liuzhou, Guangxi 545616, China \\ ${ }^{2}$ School of Economics \& Management, Guangxi University of Science and Technology, Liuzhou, Guangxi 545006, China \\ *Corresponding author. Email: 958194953@qq.com
}

\begin{abstract}
This paper aims to study the ways to cultivate applied talents in industry-empowered private colleges. The article analyzes the problems and causes in the talents cultivation in private colleges by taking the information technology major as an example, on the basis of which the multi-subject and whole-process college-enterprise collaborative cultivation method is explored from the perspective of industry-education integration, thus creatively constructing a spiral model of college-enterprise collaborative cultivation for private colleges. This model proposes measures for collaborative education, which provides some theoretical and practical references for the cultivation of applied talents in private colleges.
\end{abstract}

Keywords: Private colleges; applied talents; collaborative education; information technology major

\section{INTRODUCTION}

Under the guidance of high-quality development strategies such as 'Made in China 2025', China's manufacturing industry has been accelerating. A new generation of hightech industries represented by artificial intelligence, cloud computing and the Internet of Things has entered the fast lane of development, and the demand for high-quality applied talents has grown rapidly. Taking the information technology industry as an example, by 2023, the demand for applied talents of information technology in China has exceeded 10 million, while the cultivation of talents in colleges only accounts for one-tenth of that demand[1]. It is worth noting that the contradiction between supply and demand of talents caused by mismatch between talents cultivation in colleges and the needs of industrial development has also become an important factor in the shortage of applied talents in information technology industry.

As an important institution for cultivating applied talents, private colleges exist for a relatively a short time, accompanied by many problems in their talents cultivation, mainly in the forms of outdated talent cultivation mode and lack of connection with industries in terms of curriculum system, teaching content and education platform, which cannot meet the demand of high-quality talents for rapid development of industry.

\section{OVERVIEW OF COLLEGE- ENTERPRISE COLLABORATIVE EDUCATION}

College-enterprise collaborative education is an important institutional framework of modern vocational education, and it is also an important experience of long-term practice in education, which can be traced back to the sandwich education mode of Sunderland Technical College(UK)[2]. The college-enterprise collaborative education in China sprouted in the 1920s, was explored in the 1990s [3], developed in 2010s [4] and was formed in 2018[5]. It can be roughly divided into embryonic stage, exploration stage, development stage and forming stage (as shown in Figure1).

In embryonic stage in 1920 s, due to the need for rapid training of technical talents, a prototype of collegeenterprise collaborative education of 'working while learning' emerged in society. This stage is mainly the vocational education model run by enterprises featured by its work-oriented college-enterprise collaborative education mode while taking learning into account. In the exploration stage of 1991, the State Council issued the Decision on Vigorously Developing Vocational and Technical Education, which clarified the development mode of college-enterprise collaborative education. At this stage, enterprises help schools to build practical training (internship) bases and assist schools to complete some practical teaching tasks. However, enterprises are not very motivated to participate due to the lack of a long-term benefit-compatible mechanism. The development stage begins in 2010., The Ministry of Education released the 
National Medium and Long-term Education Reform and Development Plan (2010-2020) to clearly the specific measures for implementing the integration of industry and education. Since then, the government has introduced policies to mobilize enterprises to participate in talent cultivation in colleges and to promote a win-win mechanism between colleges and enterprises. In this stage, colleges provide technical assistance, training, site and equipment use support for enterprises, and enterprises participate in more talent training sessions, and the government acts as the fulcrum of college-enterprise cooperation, constantly balancing the interests of colleges and enterprises. In the formation stage in 2018, theories related to industrial colleges are basically mature, and the transformation from concept to entity is basically completed [6], with leading enterprises, industry associations, and industrial parks as the leaders and professional clusters as the ties to build college-enterprise cooperation platforms, thus implementing deeper and broader cooperation. IN this stage, colleges aim to deepen the construction of service-oriented teaching system and enterprises aim to improve the professional quality of employees, recruit high-quality talents, so as to promote the high-quality development of enterprises [7].

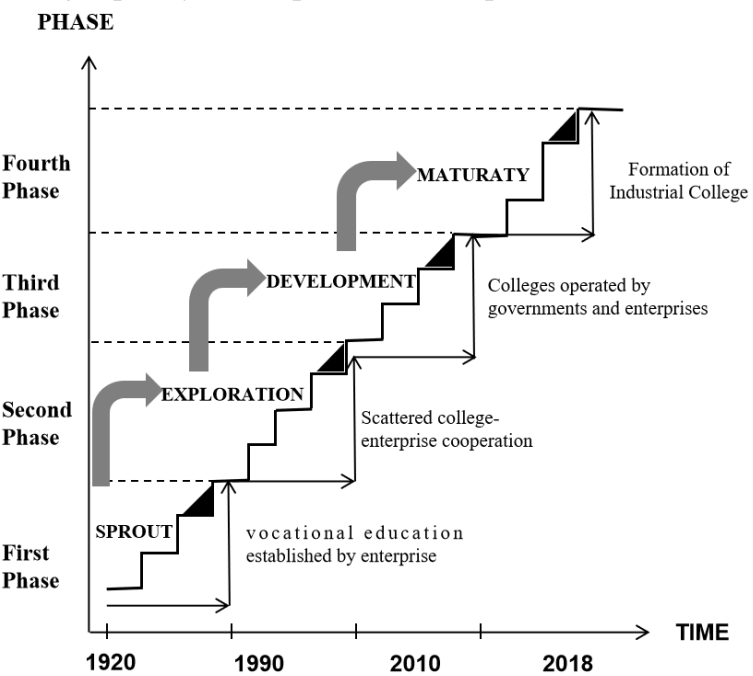

Figure 1. The development of collaborative education

In summary, college-enterprise cooperative education has changed from a few cooperation agreements in a disperse manner to the deep integration between professional groups and industrial chains. The role of enterprises in the cooperative education ecosystem has become more and more important, the process of talent training has become increasingly close to the development of industry enterprises, and the quality of talent training has become more and more compatible with industrial demands, which fully indicates that the mode can effectively break the relatively closed education ecology of colleges, meets the need between the talent training and industrial development, and effectively improve the quality of talent in college.

\section{PROBLEM AND CAUSES OF APPLIED TALENTS CULTIVATION IN PRIVATE COLLEGES}

The history of private institutions is relatively short, and the talent training programs, curriculum system, professional settings, teaching contents and teaching assessment in many institutions are mostly copied public institutions, therefore, private colleges lack the motivation to build distinctive major, and the major construction and teaching reform lag far behind the pace of industrial development. In this section, we take information technology major as an example to analyze the problems and causes for the cultivation of applied talents in private colleges.

\subsection{The Problems of Applied Talents Cultivation in Private Colleges}

\subsubsection{Lack of adjustment in major settings}

With the rapid development of information technology, the core majors under the category of information technology are rapidly popularized. Most private colleges fail to adjust their major direction, talent training objectives and curriculum system in time according to industrial needs. The history of private colleges is relatively short, and the talent cultivation ecology is relatively closed. The setting and adjustment of information technology major basically learn from similar colleges, even many colleges copy the talent cultivation scheme of information technology major from public universities. They lack the dynamic adjustment mechanism of majors that fits the laws and requirements of industrial development, and cannot achieve the seamless connection between talent cultivation objectives and industrial development requirements. Therefore, the setting and adjustment of majors lag behind the needs of industrial development.

\subsubsection{Outdated professional teaching content}

In private colleges, the teaching contents of many courses of information technology major are relatively old, which not only lag behind the speed of industrial development, but also do not meet the needs of enterprises. In addition, the course content is similar and homogenized among private colleges. The content of the practical courses differs greatly from the actual job content, even some course contents have been eliminated by the industry. Moreover, some teachers' knowledge reserves are relatively outdated, and the speed of knowledge updating lags behind the development of the industry. Most of the private colleges fail to develop new curriculum system and special curriculum contents 
according to their own characteristics and industrial and economic development in the regions they are located.

\subsubsection{Dislocation between the information technology applied talents cultivation and industry demand}

In recent years, new information technologies have emerged, the technology iteration cycle has been shortened, new jobs and new requirements keep emerging, thus it is more difficult for private colleges to adjust their talent cultivation to the development of information industry. Graduates' knowledge is not consistent with the demand of enterprises, not to mention the innovation ability and hands-on ability. Therefore, they have incorrect job orientation when they start to work. In addition, there is a shortage of top talents who have global vision and master the frontier technology of information industry. This is caused by several reasons. First, graduates blindly pursue employment in big cities, while the shortage of talent in small and medium-sized cities. Secondly, graduates tend to be employed by large enterprises in the upstream of the industry, while there is a shortage of technical talents in small and medium-sized enterprises.

\subsection{The analysis of the causes of Applied Talents Cultivation in Private Colleges}

\subsubsection{Lack the motivation for internal reform}

For a long time, private colleges basically adopt a relatively closed running mode due to its short school running history and the lack of experience for reference. The disconnection of social resources and industry demands, coupled with the special mechanism of private colleges, leads to the tension of resources, the lack of reference of enterprises, the slow update of talent cultivation mode and running resources of colleges, and the poor social adaptability of graduates. Many factors, such as the concept of school-running, and talent cultivation mode, make private colleges unable to break the quality bottleneck of talent cultivation in a short time.

\subsubsection{Disconnection with industry needs}

The relatively closed education ecology of private colleges leads to narrow channels to connect with industry. According to the research data, $63 \%$ of private colleges fail to put college-enterprise cooperative education into the actual teaching process, $79 \%$ of teachers in private colleges reflect that they lack in-depth understanding on the industry, and the common ways for these teachers to obtain the latest industry information are the Internet, seminars, enterprise visits and other non-direct channels. The interaction between private colleges and regional industry is not enough and the connection with industrial need is not close, which leads to the low matching degree between academic disciplines and regional industrial structure. Due to a more closed school professional setting, teaching environment, teaching resources, etc., it is difficult to realize the connection between the supply-side talent training and the industrial demand, thus causing a disconnection between school talent training and industrial development needs.

\subsubsection{Lack of dynamic for college-enterprise cooperation}

At present, the college-enterprise cooperation and integration of industry and teaching in private college are mostly conducted in the practical teaching process. Due to the lack of internal dynamic in industries and enterprises, an embarrassing situation where colleges are active while enterprises are passive is presented. This is because a well mechanism has not yet been built between administrationoriented colleges and market-oriented enterprises. Most applied talents in information technology are cultivated by colleges, even that a few colleges explore school-enterprise cooperation to cultivate applied talents. But due to the lack of motivation and effective mechanisms, such cooperation is not taken in an all-round way, only limiting to a few parts of talent training, thus it is unable to cultivate highquality talents in the whole process.

\section{CONSTRUCTION OF SPIRAL COLLEGE-ENTERPRISE CLLABORATIVE MODEL}

In order to promote the deep collaboration between private colleges and enterprises and further improve the collegeenterprise cooperative education mechanism, this paper constructs a progressive and multiple collaborative spiral college-enterprise collaborative education model with colleges, government and enterprises as the main body of education, with the resource sharing, complementary advantages, synergistic development and the community of shared interests of win-win cooperation as concept, and with government promotion, social drive, college promotion and enterprise linkage as the driving force (as shown in Figure 2). The model strengthens the important role of enterprises in the process of education, and aims to combine the process of talent cultivation with the operation of enterprises in order to seamlessly match talent training with industrial development, and further cultivate highquality applied talents that meet the needs of industrial development. 


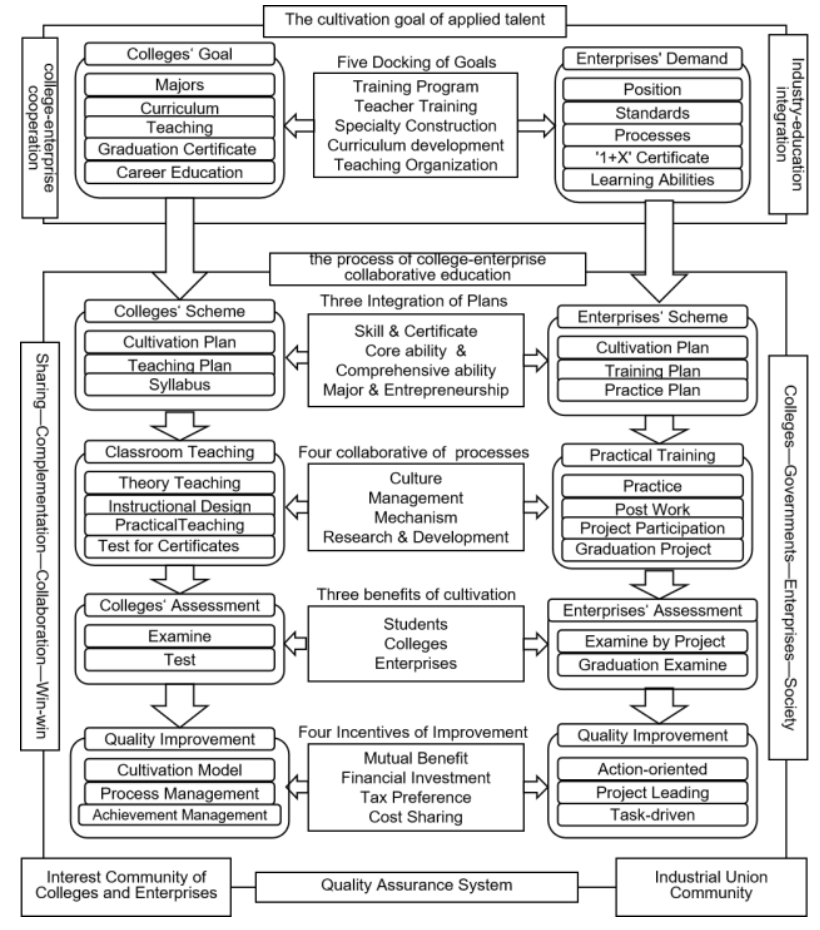

Figure 2. The spiral model of college-enterprise collaborative education

\subsection{Five ways to connect cultivation goals}

The goal of talent cultivation is the starting point of schoolenterprise cooperation, and private colleges should connect their own cultivation orientation with enterprises' demand. Firstly, it should connect with the target in the formulation of talents cultivation plan. Colleges should connect the professional construction goals and curriculum construction goals with the job standards and career standards of enterprises in order to make clear the goal of talents cultivation for industry enterprise jobs. Secondly, it should connect with the target in teachers' cultivation. Colleges should prompt teachers to update their professional knowledge in time according to the industry development. Thirdly, it should connect the target in professional building. Colleges should organically combine the major construction goals with enterprise standards to achieve parallel development of colleges and enterprises. Fourth, it should connect with target in curriculum development. Colleges should ensure that the course objectives are the job requirements in industry. Fifth, it should connect the target in teaching objectives. Colleges should introduce the job activities of enterprises into the teaching, and organically combine the teaching goal achievement with the industry skill certification. In addition, lifelong learning in colleges should also continue in work with developing lifelong learning of professional skills.

\subsection{Three integration of cultivation plan}

Cultivation plan is the specific arrangement of talent cultivation. Private colleges should revise the cultivation plan with reference to the technical talent training program of enterprises, and break the barrier between cultivation plan and the training program of enterprises. Firstly, colleges should integrate the job skill requirements of talent cultivation with the vocational skill certificate. Secondly, in the plan of cultivation, colleges should combine the cultivation plan with enterprises' training plan, and theoretical teaching plan with enterprises' practical training plan to realize the integration of core literacy and comprehensive quality. Finally, both colleges and enterprises should take advantage of their strengths in the development of cultivation plan to achieve the integration of majors education and entrepreneurship education, so as to cultivate new applied talents with both high professionalism and entrepreneurial ability.

\subsection{Four collaborative of cultivation processes}

The cultivation process is an important part of collegeenterprise collaborative education, and a well-coordinated relationship plays a key role in promoting high-quality talent cultivation. Therefore, the first step is to establish cultural synergy and introduce the culture of the industry into the teaching in colleges, so as to promote the cultural consistency between colleges and enterprises. Secondly, through management synergy, the huge difference between free management mode in colleges and standardized management in industries and enterprises can be solved, which can prompt graduates to adapt to the industry as soon as possible. Thirdly, colleges should strengthen the industry system education, so that graduates can quickly adapt to the work requirements after entering the enterprises. Finally, colleges should introduce scientific research achievements of teachers and workers into the talent cultivation process, so as to realize that the advantageous resources can be fully utilized in talent cultivation.

\subsection{Three way of mutual evaluation in cultivation effect}

It is especially important to combine college assessment with enterprise assessment. Therefore, it is necessary to build an assessment mechanism centered on the effectiveness of student cultivation, with students, colleges and enterprises. The first step is to establish a system for students to evaluate the teaching resources and teaching process of the colleges and enterprises respectively, and then evaluate the teaching conditions and teaching capabilities of the colleges and enterprises. The second step is to establish an evaluation system on the students' learning and assess the effect of enterprises' participation in co-education. Finally, enterprises should establish an 
evaluation of the effectiveness of colleges' education from the perspective of industrial development.

\subsection{Four incentives for quality improvement}

Quality improvement is the last important part of talent training, and the core of its work is to connect the quality improvement of college with that of enterprises, for example, the action-oriented, project-led and task-driven elements of enterprise quality control should be integrated into the quality evaluation of colleges. In order to achieve this, both colleges and enterprises should continue to explore the scope and potential of the "win-win" project, increase the financial investment of both sides, share the cost of improvement work, and the local government should give tax incentives to enterprises, so as to stimulate the quality improvement of college-enterprise cooperation in talent cultivation.

\section{MEASURES TO IMPROVE THE QUALITY OF APPLIDE TALENTS IN PRIVATE COLLEGES}

According to the spiral school-enterprise collaborative education model, private colleges can improve the quality of applied talents cultivation in terms of college-enterprise cooperation system, major setting and cultivation mode, etc. This section takes information technology major as an example and gives strategies for private colleges to improve the quality of applied talents cultivation.

\subsection{Improving the college-enterprise cooperation system}

Private colleges should constantly improve the mechanism of college-enterprise cooperation to ensure that the cooperation advances in the direction of a deep collaborative education with multiple subjects and open forms. In order to make the cooperation run effectively, colleges should introduce a series of systems and norms to promote the virtuous cycle and circulation of talents, technologies and funds between the school and enterprises, such as the interest alliance building, collaborative education model and its process execution, collaborative scientific research cooperation, etc.

\subsection{Optimizing the setting of majors}

Private colleges should keep an eye on the dynamic adjustment of majors in industrial development, work with enterprises to optimize the professional settings, create professional clusters with self-evolutionary ability, drive the connotative development of other related majors with the core of advantageous characteristic majors, and enhance the adaptability of professional talents training.
Private colleges should focus on the needs of emerging industries, add new engineering majors such as data science and big data technology, computer science and technology, new media technology, cyberspace security, Internet of things, intelligent science and technology, and intelligent manufacturing engineering. In addition, private colleges should eliminate some majors that cannot adapt to the changing needs of the society and enhance the match between the layout of majors and the development of local industries.

\subsection{Reforming the talent training model}

Private colleges should actively implement "dual-subject" school running in accordance with the development characteristics of information technology in different phase explore talent cultivation models and mechanism in which leading enterprises play a key role and different social subjects participate in, break the inherent barrier between the teaching ecology in colleges and operation ecology in industries and enterprise, and build a modern industrial college so as to jointly solve the problems of students professional learning, internship, graduation design and employment. Students' curriculum system is built in the colleges-enterprise cooperation. Moreover, it can improve their vocational ability and professionalism. Meanwhile, we should actively explore the teaching task system focusing on project teaching, case teaching and job teaching, and form a quality evaluation committee composed of enterprise experts, college teachers, etc. to conduct real-time evaluation of the applied talent system and its effects.

\subsection{Co-building industry-learning platform for talents education}

Private colleges should join hands with enterprises to establish practical platforms for students' learning activities and provide platforms for students' innovative practical activities, such as virtual reality open classrooms, complex still life rapid modeling labs, virtual reality content production centers, graphics workstation labs and big data service bases, etc. These platforms will promote the twoway flow of technology in education and industry, improve the effectiveness and practicality of teaching activities, and strengthen students' creative and practical abilities, enabling students to master work skills while learning their majors and enhance their vocational abilities while obtaining academic degrees.

\subsection{Creating a diversified teaching team}

Teachers are the "helmsman" of the development of colleges and directly influence the direction and quality of talent cultivation. In order to break through the selfcirculation ecosphere of college, private colleges should 
actively introduce famous technical experts from enterprises to participate in talent cultivation, and establish open and mixed faculty through joint teaching and research, joint training, joint guidance and other measures. At the same time, private colleges should assign teachers to participate in enterprises' project in the form of full-time or part-time, so as to drive the two-way flow of industry information and technology between colleges and enterprises through the two-way flow of personnel.

\section{CONCLUSION}

This paper analyzes the problems in talent cultivation in private colleges, such as the closed cultivation mode, lack of dynamics in school-enterprise cooperation internal motivation in cultivation, and the disconnection between talent cultivation quality and enterprise demand. Based on this, this paper proposes the college-enterprise collaborative education model and gives the following suggestions for private colleges to improve talent quality: private colleges should build college-enterprise collaborative cultivation ecology, make full use of industrial power to empower the talent cultivation process, improve the institutional mechanism of college-enterprise collaborative cultivation, connect the talent cultivation process with the operation of enterprises, dynamically adjust majors, reform the talent cultivation mode, build a mixed cultivation platform, and the talent cultivation platform. At the same time, it should improve the institutional mechanism of cooperative education, connect the process of talent cultivation with the operation of enterprises, dynamically adjust the majors, reform the talent cultivation mode, build the cultivation platform and create a mixed teaching team, so as to cultivate highquality applied talents that meet the industrial needs.

\section{ACKNOWLEDGMENT}

The authors are grateful for the constructive comments of the reviewer of the earlier version of this paper. In addition, this work was supported by following grants:

1) Exploration of the information technology professional talent training model based on "dual-mode IT" and " $1+2+\mathrm{X}$ course module", No. 2020JGZ174;
2) Research on the Practice Education Mode of "Mass Entrepreneurship and Innovation" in Applied Universities Based on School-Enterprise Cooperation, No. $2021 Z C L L 15$.

\section{REFERENCES}

[1] Ke Liang. Research on the theory and practice of training information technology talents in the context of big data[J]. Information Record Materials,2019,20(02):217-218.

[2]Xiongfei Yin. The construction of government-led school-enterprise cooperation promotion mechanism[J]. Education and Career,2012(33):8-10.

[3] Jianhua Xu. Historical changes and development trend of school-enterprise cooperation in China[J]. Vocational and technical education,2009,30(07):39-41.

[4] Yun Xiao, Zhonglin Guo. A review of research on the integration of industry and education in applied undergraduate institutions $[\mathrm{J}]$. Cooperative Economics and Technology,2021(01):100-102.

[5] Yan Li,Jishui Wang. Research on industrial colleges in China: process and trend--a literature study based on CNKI core journals in the past 10 years[J]. China Vocational and Technical Education,2020(03):22-27.

[6] Hongli Zhou, Shenggang Wu. A review of the evolution of industrial colleges in higher education institutions[J]. China Vocational and Technical Education,2021(18):65-69+74.

[7] Ai Huang, Zhiyong Zhu. Research and practice of building a professional construction mechanism for industrial colleges to improve the quality of higher vocational talents training[J]. Vocational Education Forum,2015(18):65-68. 